\title{
Development and Human-Animal Interaction
}

\author{
Commentary on Mueller \\ Karinna B. Hurley \\ Human Ecology and Center for Mind and Brain, University of California, Davis, Calif., USA
}

\begin{abstract}
Key Words
Commentary $\cdot$ Development $\cdot$ Human-animal
\end{abstract}

Over the past several decades there has been a steady increase in research on human-animal interaction (HAI). Dozens of measures have been developed [see Anderson, 2007] to understand peoples' attachment to animals and connections between those relations with health and psychological outcomes. While much of this focus has been adult-centered, research has established pets as significant members of some children's and adolescents' family systems [Albert \& Bulcroft, 1988; Cain, 1983; Covert, Whiren, Keith, \& Nelson, 1985] and identified links between children's relationships with pets to positive socio-emotional development [Daly \& Morton, 2006; Davis, 1987; Poresky, Hendrix, Mosier, \& Samuelson, 1988] - possibly stemming from increased social support [Bryant, 1985; Melson, Peet, \& Sparks, 1992; Morrow, 1998]. Less work has focused on relationships between children and other types of animals. While these findings are both promising and intriguing, there is a problematic lack of a theoretical framework guiding much of this research [Barba, 1993; Beck \& Katcher, 2003]. And, although some studies have addressed developmental issues (e.g. the development of empathy) [Vizek-Vidovic, Stetic, \& Bratko, 1999], there has been little attempt to situate HAI within a broader developmental framework. This is surprising, overall, given that theory has guided and structured much of the past and current empirical work on child and adolescent development. Consider, for example, how constructivist or nativist theories and models of development have driven research questions and directions on cognitive development. Mueller's [this issue] Human-animal interaction as a context for positive youth development: A relational developmental systems approach to constructing human-animal interaction theory and research, is a welcome proposal for grounding HAI research in a developmental systems model from which to develop theory and research. This

\begin{tabular}{ll}
\hline KARGER & $\odot$ 2014 S. Karger AG, Basel \\
$\begin{array}{l}\text { E-Mail karger@karger.com } \\
\text { www.karger.com/hde }\end{array}$ &
\end{tabular}

Karinna B. Hurley

Human Ecology and Center for Mind and Brain

University of California

Davis, CA 95618 (USA)

E-Mail kbhurley@ucdavis.edu 
contribution is significant because it provides a basis for developing systematic studies on HAI and development. Mueller focuses on using this model to study positive youth development (PYD) [Lerner et al., 2012], but indeed her proposed framework can even be applied more broadly to other aspects of development.

Mueller highlights two strengths in structuring HAI research using a relational developmental systems theory approach (RDST) [Overton, 2010; Overton \& Mueller, 2012]. First, an RDST-based approach is developmental. Much of the existing research on HAI addresses linear associations between an animal and a particular outcome in a human (e.g. stress, heart rate, compliance in a therapeutic intervention) [Friedmann, Thomas, Stein, \& Kleiger, 2003; Melson, Schwarz, \& Beck, 1997; Roberts, Bradberry, \& Williams, 2004]. While establishing such relationships is valuable and necessary, developmental research exploring how HAI influences and interacts with the variety of factors that contribute to individual and age-related change over time is an exciting prospect. And, as Mueller suggests, it would be worthwhile to understand how relationships with animals themselves change and develop over time.

Second, studies developed from an RDST perspective would consider how HAI influences both the people and the animals in the relationships. This is important because relationships, by nature, are bi-directional. For example, not only do parents influence the development of their children, but children influence parents and their behavior as well [e.g. Bell, 1968]. Accordingly, it makes sense that considering the development of the animals in child-animal relationships would give us a more rich understanding of developmental processes.

Mueller also considers the ways that an RDST approach can be used to understand the role of animals in contributing to PYD and identifies several possible domains of adaptive HAI including: purpose, the development self-regulation, social and moral reasoning skills, and physical health. Mueller provides background for each domain and suggests some ways that animals have the potential to make a unique contribution to development. For example, in terms of the development of one's sense of purpose, HAI might provide a context for engaging in long-term and meaningful goals and relationships. For the domains such as the development of social skills that have received some research attention, Mueller reviews the relevant studies and provides suggestions for further directions. Importantly, she does not overlook the complexities such research will need to take into account, such as the differences in the type of relationship youths can have with animals (e.g. livestock vs. pets) in different contexts (e.g. competitive vs. educational), nor how differences in youths' racial, ethnic, or cultural backgrounds might influence the ways they interact with animals. It is important as well to consider how differences between animals, both between species and individuals, might influence HAI. It seems probable that different species will have different potential impact in PYD in each domain. For example, several species of animals might be able to serve as social facilitators or sympathetic others for youths to express emotions to - two potential roles Mueller identifies for animals in promoting social development. However, as she also points out, some companion animals (dogs) are particularly sensitive to social interactions with people [Téglás, Gergely, Kupán, Miklósi, \& Topál, 2012]. Perhaps, given their unique abilities and evolutionary history with humans [Hare, Brown, Williamson, \& Tomasello, 2002; Miklósi, Kubinyi, Topál, Gácsi, Virányi, \& Csányi, 2003], Mueller suggests that dogs are much more suited to another research 
focus - understanding the parallels and differences between human-animal and human-human relationships. Furthermore, individual animals within the same species will bring their own unique personalities [Gosling \& Bonnenburg, 1998] and traits into HAI. It will be important for researchers to carefully consider variability within and between different types of animals when developing studies to target various developmental questions.

In addition to the several domains that were identified in this commentary, another potential area of PYD that should be considered is cognitive development. Particularly early in development, interactions with animals seem to influence developing cognitions about animals. "Cat" and "dog" appear to be among children's first spoken words [Tardif, Fletcher, Liang, Zhang, Kaciroti, \& Marchman, 2008], perhaps because they are such salient members of some children's lives. In several studies, including infants with and without pets in the home, Kovack-Lesh, Oakes, and colleagues [Hurley, Kovack-Lesh, \& Oakes, 2010; Hurley \& Oakes, in press; KovackLesh, Horst, \& Oakes, 2008; Kovack-Lesh, McMurray, \& Oakes, 2014; Kovack-Lesh, Oakes, \& McMurray, 2012] have demonstrated experience with a cat or dog contributes to infants' processing of animal images in laboratory tasks. Even experience with just images of animals has been shown to have an effect on infants' processing of animal faces [Pascalis et al., 2005; Scott \& Monesson, 2009].

Developing sophisticated cognitions about animals could contribute to PYD in significant ways. Indeed, having an animal at home seems to influence children's knowledge and reasoning about animals [Hatano \& Inagaki, 1993; Prokop, Prokop, \& Tunnicliffe, 2008]. In her discussion of moral development, Mueller suggests animals might provide a context for increased opportunities for perspective-taking. Such opportunities have the potential to benefit youths beyond their moral cognitions and benefit cognitive development more generally. For example, HAI and increased perspective-taking in childhood could lead to earlier or more sophisticated theory-ofmind development, while HAI in general could lead to more sophisticated cognitions about animals including essentialism and/or biology.

There may be additional domains where HAI can contribute to PYD, and the RDST approach Mueller proposes to think about these can be an excellent starting point for researchers. Finally, while her focus is on the possible mutually beneficial outcomes in each domain she identifies, ultimately it will be important to also consider the potential negative outcomes of HAI for both children and animals.

Finally, Mueller addresses some of the complexities inherent in the various instantiations of HAI and how an RDST approach can focus future research. She concentrates on three features of HAI experience: the structure, quality, and type of animal involved. Mueller raises important questions and points of consideration for each feature, such as how cultural context may impact the quality of relationships with animals. In terms of the impact of the type of animal on HAI and development, Mueller highlights the need for more research exploring the factors that lead youths to engage with some animals over others, especially given that different animals (e.g. a pig raised for food purposes vs. a housecat) will likely be associated with different types of developmental outcomes. Again, the type of animal and both individual and species-level attributes will be important factors to consider.

Mueller concludes her paper by suggesting several excellent future steps in HAI research. In summary, her article makes an important contribution to our thinking about HAI and development. By outlining how a developmental systems-based ap- 
proach can be applied to HAI and development, Mueller addresses how researchers can potentially overcome a particularly challenging aspect of HAI research - considering the complexities of bi-directional dynamic relationships. Seeking to understand the ways HAIs contribute to positive human developmental outcomes provides an excellent basis for structuring and developing meaningful theory-based programs of research. Mueller has grounded her ideas in the current HAI literature, providing researchers with a picture both of where we have been and where we can go.

\section{References}

Albert, A., \& Bulcroft, K. (1988). Pets, families, and the life course. Journal of Marriage and the Family, 50, $543-552$.

Anderson, D.C. (2007). Assessing the human-animal bond: A compendium of actual measures. West Lafayette: Purdue University Press.

Barba, B.E. (1993). A critical review of research on the human/companion animal relationship: 1988 to 1993. Anthrozoös, 8, 9-20.

Beck, A.M., \& Katcher, A.H. (2003). Future directions in human-animal bond research. American Behavioral Scientist, 47, 79-93.

Bell, R.Q. (1968). A reinterpretation of the direction of effects in studies of socialization. Psychological Review, 75, 81-95.

Bryant, B.K. (1985). Sources of support derived from the neighborhood walk. Monographs of the Society for Research in Child Development, 50, 34-44.

Cain, A. (1983). A study of pets in the family system. In A. Katcher \& A. Beck (Eds.), New perspectives on our lives with companion animals. Philadelphia: University of Pennsylvania Press.

Covert, A.M., Whiren, A.P., Keith, J., \& Nelson, C. (1985). Pets, early adolescents, and families. Marriage \& Family Review, 8, 95-108.

Daly, B., \& Morton, L.L. (2006). An investigation of human-animal interactions and empathy as related to pet preference, ownership, attachment, and attitudes in children. Anthrozoös, 19, 113-127.

Davis, J.H. (1987). Pre-adolescent self-concept development and pet ownership. Anthrozoös, 1, 90-94.

Friedmann, E., Thomas, S.A., Stein, P.K., \& Kleiger, R.E. (2003). Relation between pet ownership and heart rate variability in patients with healed myocardial infarcts. American Journal of Cardiology, 91, $718-721$.

Gosling, S.D., \& Bonnenburg, A.V. (1998). Integrating personality research in anthrozoology: Ratings of six species of pets and their owners. Anthrozoös, 11, 148-156.

Hare, B., Brown, M., Williamson, C., \& Tomasello, M. (2002). The domestication of social cognition in dogs. Science, 298, 1634-1636.

Hatano, G., \& Inagaki, K. (1993). Desituating cognition through the construction of conceptual knowledge. In G. Salomon (Ed.), Distributed cognitions (pp. 115-133). New York: Cambridge University Press.

Hurley, K.B., Kovack-Lesh, K.A., \& Oakes, L.M. (2010). The influence of pets on infants' processing of cat and dog images. Infant Behavior and Development, 33, 619-628.

Hurley, K.B., \& Oakes, L.M. (in press). Experience and distribution of attention: Pet exposure and infants' scanning of animal images. Journal of Cognition and Development.

Kovack-Lesh, K.A., Horst, J., \& Oakes, L.M. (2008). The cat is out of the bag: The joint influence of previous experience and looking behavior on infant categorization. Infancy, 13, 285-307.

Kovack-Lesh, K.A., McMurray, B., \& Oakes, L.M. (2014). Four-month-old infants' visual investigation of cats and dogs: Relations with pet experience and attentional strategy. Developmental Psychology, 50, 402-413.

Kovack-Lesh, K.A., Oakes, L.M., \& McMurray, B. (2012). Contributions of attentional style and previous experience to 4-month-old infants' categorization. Infancy, 17, 324-338.

Lerner, J.V., Bowers, E.P., Minor, K., Boyd, M.J., Mueller, M.K., Schmid, K.L., Napolitano, C.M., LewinBizan, S., \& Lerner, R.M. (2012). Positive youth development. In J.V. Lerner, M.A. Easterbrooks, \& J. Mistry (Eds.), Handbook of psychology, second edition. Vol. 6 (pp. 365-392). New York: Wiley.

Melson, G.F., Peet, S., \& Sparks, C. (1992). Children's attachment to their pets: Links to socioemotional development. Children's Environments Quarterly, 8, 55-65.

Melson, G.F., Schwarz, R.I., \& Beck, A.M. (1997). Importance of companion animals in children's lives - Implications for veterinary practice. Journal of the American Veterinary Medical Association, $211,1512-1518$. 
Miklósi, A., Kubinyi, E., Topál, J., Gácsi, M., Virányi, Z., \& Csányi, V. (2003). A simple reason for a big difference: wolves do not look back at humans, but dogs do. Current Biology, 13, 763-766.

Morrow, V. (1998). My animals and other family: Children's perspectives on their relationships with companion animals. Anthrozoös, 11, 218-226.

Overton, W.F. (2010). Life-span development: Concepts and issues. In R.M. Lerner (Ed.), Handbook of life-span development. Vol. 1. Hoboken, NJ: Wiley.

Overton, W.F., \& Mueller, U. (2012). Meta-theories, theories, and concepts in the study of development. In R.M. Lerner, M.A. Easterbrooks, \& J. Mistry (Eds.), Comprehensive handbook of psychology: Developmental psychology. Vol. 6 (pp. 19-58). New York: Wiley.

Pascalis, O., Scott, L.S., Kelly, D.J., Shannon, R.W., Nicholson, E., Coleman, M., \& Nelson, C.A. (2005). Plasticity of face processing in infancy. Proceedings of the National Academy of Sciences of the United States of America, 102, 5297-5300.

Poresky, R.H., Hendrix, C., Mosier, J.E., \& Samuelson, M.L. (1988). Children's pets and adults' self-concepts. The Journal of Psychology, 122, 463-469.

Prokop, P., Prokop, M., \& Tunnicliffe, S.D. (2008). Effects of keeping animals as pets on children's concepts of vertebrates and invertebrates. International Journal of Science Education, 30, 431-449.

Roberts, F., Bradberry, J., \& Williams, C. (2004). Equine-facilitated psychotherapy benefits students and children. Holistic Nursing Practice, 18, 32-35.

Scott, L.S., \& Monesson, A. (2009). The origin of biases in face perception. Psychological Science, 20, 676680.

Tardif, T., Fletcher, P., Liang, W., Zhang, Z., Kaciroti, N., \& Marchman, V.A. (2008). Baby’s first 10 words. Developmental Psychology, 44, 929-938.

Téglás, E.Q., Gergely, A., Kupán, K., Miklósi, Á., \& Topál, J. (2012). Dogs' gaze following is tuned to human communicative signals. Current Biology, 22, 209-212.

Vizek-Vidovic, V., Stetic, V., \& Bratko, D. (1999). Pet ownership type of pet and socio-emotional development of school children. Anthrozoös, 12, 211-217. 